\section{HEMOSTATIC FUNCTION OF ASPIRIN-TREATED PLATELETS VULNERABLE TO CARDIOPULMONARY BYPASS}

\author{
Altered shear-induced \\ pathway
}

The impaired hemostasis of aspirin-treated patients is an annoying problem during and after cardiopulmonary bypass. The hemostatic function of platelets comprises two mechanisms: the shear-induced and the cyclooxygenase pathways. Because the latter is inhibited in aspirin-treated patients, the hemostatic function depends mainly on the former pathway. To investigate the effect of cardiopulmonary bypass on the shear-induced pathway, a double-blind study of preoperative aspirin treatment $(325 \mathrm{mg}$ ) and placebo was conducted in $\mathbf{4 0}$ patients undergoing coronary artery bypass grafting. Postoperative blood loss was higher in the aspirin-treated patients than in the placebo-treated patients $(p<0.05)$. The shear-induced hemostasis was monitored by the in vitro bleeding test (Thrombostat), which mimics bleeding through an injured arteriole. The shear-induced pathway of aspirin-treated platelets was not affected before cardiopulmonary bypass, but it was impaired more during the operation $(p<0.01)$ and remained worse afterward $(p<0.05)$, compared with that of placebotreated platelets. The inhibitory effects of aspirin on thromboxane production and on collagen-induced platelet aggregation remained throughout the operation. In aspirin-treated platelets, the aggregation capacity induced by adenosine diphosphate was inhibited before the operation $(p<0.05)$ and showed substantial recovery during the operation $(p<0.05)$. These results suggest that the shear-induced pathway of aspirin-treated platelets is more vulnerable to cardiopulmonary bypass than the pathway in normal platelets and causes severe impairment of hemostasis afterward. (J THORAC Cardiovasc Surg 1995;110:813-8)

Noriyuki Tabuchi, MD, ${ }^{\text {a }}$ Rolf C. G. Gallandat Huet, MD, PhD, ${ }^{b}$ Augueste Sturk, $\mathrm{PhD},{ }^{\mathrm{c}}$ Leon Eijsman, $\mathrm{MD}, \mathrm{PhD},{ }^{\mathrm{d}}$ and

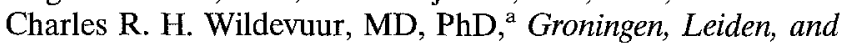
Amsterdam, The Netherlands
A spirin treatment has become standard for patients who have coronary artery disease. ${ }^{1}$ If aspirin-treated patients must undergo coronary artery bypass grafting (CABG), the concern is the risk of increased bleeding during and after the opera-

From the Thorax Center ${ }^{\mathrm{a}}$ and Department of Anesthesia, ${ }^{\mathrm{b}}$ University Hospital Groningen, Department of Clinical Chemistry, University Hospital Leiden, ${ }^{c}$ and Department of Cardiopulmonary Surgery, Academic Medical Center, ${ }^{\mathrm{d}}$ Amsterdam, The Netherlands.

Financially supported by Bayer AG, Leverkusen, Germany.

Received for publication July 20, 1994.

Accepted for publication Dec. 22, 1994.

Address for reprints: C. R. H. Wildevuur, MD, Department of Cardiopulmonary Surgery, Research Division, University Hospital, Oostersingel 59, 9713 EZ Groningen, The Netherlands.

Copyright (c) 1995 by Mosby-Year Book, Inc.

$0022-5223 / 95 \$ 5.00+0 \quad \mathbf{1 2 / 1 / 6 3 3 4 6}$ tion. ${ }^{1-4}$ Aspirin-treated patients who undergo surgical procedures without cardiopulmonary bypass (CPB) manifest mild but not profound impairment of hemostasis. ${ }^{5,6}$ Moreover, aspirin treatment that is begun immediately after CPB is not associated with increased bleeding. ${ }^{7}$ The hemostatic function of aspirin-treated platelets may therefore be more vulnerable to CPB than that of normal platelets, resulting in more severe impairment of hemostasis during and after CPB.

The hemostatic function of platelets comprises two mechanisms: the shear-induced pathway and the cyclooxygenase pathway. ${ }^{8,9}$ In a recent study, we $^{10}$ demonstrated that the shear-induced pathway of normal platelets is affected by the CPB procedure. Because the cyclooxygenase pathway is completely inhibited in aspirin-treated platelets, their hemostatic function mainly depends on the shearinduced pathway. Therefore, a double-blind, place- 
bo-controlled study of preoperative aspirin treatment $(325 \mathrm{mg})$ was conducted to investigate the contribution of the shear-induced pathway to hemostasis of patients undergoing CABG.

To measure changes in the shear-induced pathway, we introduced the in vitro bleeding test (Thrombostat 4000R, VDG-von der Goltz, Seeon, Germany). In this test, blood is perfused through a capillary (inner diameter $190 \mu \mathrm{m}$ ) under constant pressure $(40 \mathrm{~mm} \mathrm{Hg})$ until the shear stress causes a platelet hemostatic plug to form on a collagen filter at the end of the capillary. ${ }^{11}$ The test sensitively reflects the function of both platelet adhesion and aggregation under shear stress. ${ }^{12,}{ }^{13}$ For comparison, the conventional tests for platelets were also performed: platelet aggregation tests, plasma concentrations of platelet secretory products, and the in vivo bleeding test.

\section{Patients and methods}

Patients. After informed consent was obtained from the patients and approval from the institutions review board, 40 patients undergoing primary, elective CABG entered the randomized, double-blind, placebo-controlled study. None of the patients was more than 75 years old, and none had evidence of severe heart failure, renal or hepatic dysfunction, or bleeding diathesis. None of the patients was treated with drugs that affect platelet function within 10 days before the operation. None of the patients showed abnormal values on the thrombotest before the operation.

Protocol. Forty patients were treated with a study tablet containing aspirin $(325 \mathrm{mg})$ or placebo 10 hours before the operation. The study tablets were prepared in the pharmacology department of the University Hospital Groningen according to a randomized code. The code was unknown to all clinicians and investigators until after all parameters were obtained. Blood loss was determined during and after the operation. Blood samples were taken during the operation to test the platelet function.

Operative techniques. Anesthesia was induced with sufentanil (Janssen, Tilburg, The Netherlands) and with muscle relaxant, pancuronium bromide (Organon Teknika, Boxtel, The Netherlands). Analgesia was continued with sufentanil and midazolam (Roche, Mijdrecht, The Netherlands). Bovine heparin (300 IU/kg, Leo, Emmen, The Netherlands) was administered intravenously before cannulation, and additional heparin $(100 \mathrm{IU} / \mathrm{kg})$ was given every 60 minutes during CPB. A membrane oxygenator (COBE Laboratories, Inc., Arvada, Colo.) was primed with $2000 \mathrm{ml}$ of oxypolygelatin (Gelifundol, Biotest Pharma GmbH, Dreiech, Germany) and $1500 \mathrm{IU}$ of bovine heparin. CPB was performed with moderate hypothermia ( $28^{\circ} \mathrm{C}$ nasopharyngeal temperature) with a pump flow of $2.4 \mathrm{~L} / \mathrm{m}^{2}$ per minute and a mean arterial pressure of 50 to $60 \mathrm{~mm} \mathrm{Hg}$. After CPB, heparin was neutralized by protamine chloride $(3 \mathrm{mg} / \mathrm{kg}$, Hoffmann-La Roche BV, Mijdrecht, The Netherlands). The activated clotting time was confirmed to be longer than 400 seconds during CPB in every patient.

Blood loss during and after operation. Total hemoglobin loss during operation was determined by measuring the volume and the hemoglobin concentration of the content of the suction reservoir and of the rinse water after lysis of the red blood cells in all used gauzes. Total hemoglobin loss after operation was determined by measuring the volume and the hemoglobin concentration of the drainage blood until 12 hours after the operation. This content was anticoagulated with $5 \mathrm{ml}$ ethylenediaminetetraacetic acid $(0.4 \mathrm{~mol} / \mathrm{L})$.

The in vivo bleeding time. The measurement was performed before operation by the Ivy method.

Blood samples. At the induction of anesthesia, $5 \mathrm{~min}$ utes after the heparin injection, 5 minutes and 30 minutes after the start of $\mathrm{CPB}$, at the end of $\mathrm{CPB}$, and 30 minutes after protamine infusion, blood samples were taken from the radial arterial line or the arterial line of the oxygenator. Blood samples were collected in $0.38 \%$ sodium citrate. Indomethacin and diethylcarbamazine (final concentration of each $50 \mu \mathrm{g} / \mathrm{ml}$ ) were immediately added to an aliquot for the assays of platelet secretory products. Citrated blood was immediately used for the in vitro bleeding test and for hematologic measurements, and the remainder was centrifuged for 15 minutes at $90 \mathrm{~g}$ and $1000 \mathrm{~g}$ to obtain platelet-rich plasma and platelet-poor plasma, respectively.

The in vitro bleeding test (Thrombostat). The instrument (Thrombostat 4000R) and the analysis of the in vitro bleeding test (Baxter Diagnostics AG, Dudingen, Switzerland) have been reported in detail. ${ }^{11-13}$ The test was designed to mimic the primary hemostasis in an injured arteriole. In brief, citrated whole blood was perfused through an artificial vessel under constant pressure (40 $\mathrm{mm} \mathrm{Hg}$ ). This artificial vessel consists of a Teflon capillary (inner diameter $190 \mu \mathrm{m}$, length $20 \mathrm{~mm}$ ) that ends in a cellulose acetate filter aperture (inner diameter $150 \mu \mathrm{m}$ ) covered with collagen type I and soaked with $40 \mu \mathrm{l}$ of adenosine diphosphate (ADP; $10^{-2} \mathrm{M}$ ). The total in vitro bleeding volume was measured until blood flow through the capillary was completely stopped by a platelet plug at the end of the capillary. If the bleeding exceeded a total volume of $1000 \mu \mathrm{l}$, the measurement was stopped. The measurement was performed in the later half of the patients in the study. Eventually, the data were obtained in eight patients of each treatment group.

Laboratory tests. Platelet aggregation induced by collagen (bovine collagen type I, Sigma Chemical Company, St. Louis, Mo.; final concentration $1 \mu \mathrm{g} / \mathrm{ml}$ ) or ADP (final concentration $2 \mu \mathrm{M}$ ) in platelet-rich plasma was tested with an aggregometer (Payton 300B, Payton Association Ltd., Ontario, Canada). Maximum aggregation was expressed as a percentage of the platelet-rich plasma or platelet-poor plasma setting. The plasma concentrations of thromboxane $\mathrm{B}_{2}$ and of $\beta$-thromboglobulin were determined by enzyme immunoassay and by radioimmunoassay (Cayman Co., Ann Arbor, Mich., and Amersham International, Ltd., Little Chalfont, Bucks, United Kingdom respectively). Hemoglobin, hematocrit, and platelet number were determined with a cell counter (Cell-Dyn 610, Sequoia-Turner Corp., Mountain View, Calif.). 
Table I. Demographic data for the two study groups

\begin{tabular}{lccc}
\hline & $\begin{array}{c}\text { Placebo } \\
(n=18)\end{array}$ & $\begin{array}{c}\text { Aspirin } \\
(n=17)\end{array}$ & \\
\hline Age (yr) & $58.1 \pm 8.7$ & $60.2 \pm 7.9$ & NS \\
Body weight $(\mathrm{kg})$ & $77.3 \pm 9.7$ & $78.1 \pm 9.5$ & NS \\
CPB time (min) & $84.3 \pm 48.1$ & $87.2 \pm 22.9$ & NS \\
Number of coronary & $2.7 \pm 0.9$ & $2.8 \pm 1.0$ & NS \\
$\quad$ anastomoses & & & \\
\hline
\end{tabular}

All values are mean \pm standard deviation. NS, No statistical significance between groups.

Statistics. The Mann-Whitney $U$ test and the Wilcoxon signed rank test were used for comparison of the data between groups and within groups, respectively. All data were expressed as mean \pm standard deviation. A $p$ value less than 0.05 was considered significant.

\section{Results}

Demographic data showed no significant differences between aspirin- and placebo-treated groups (Table I). Surgical bleeding was found during rethoracotomy in three patients from the aspirin-treated group. The protocol could not be followed for logistic reasons in two patients from the placebo group. These five patients were excluded from the subsequent analysis.

Blood loss. The amount of hemoglobin loss tended to be higher in the aspirin-treated group than in the placebo-treated group both during and after the operation, although the difference was significant only after the operation $(p<0.05)$ (Fig. $1)$.

The in vitro bleeding test (Thrombostat). Before $\mathrm{CPB}$, the in vitro bleeding volume was similar in the two groups. At 5 minutes after the start of $\mathrm{CPB}$, the in vitro bleeding volume had increased substantially in both groups $(p<0.01)$. At 30 minutes after the start of $\mathrm{CPB}$, the in vitro bleeding volume had further increased, and it was significantly higher in the aspirin-treated group than in the placebotreated group $(p<0.01)$. This significantly higher in vitro bleeding volume persisted until the end of operation in the aspirin-treated group $(p<0.05)$ (Fig. 2).

The in vivo bleeding test. The Ivy bleeding time before operation was significantly longer in the aspirin-treated group than in the placebo-treated group ( $277 \pm 15$ versus $197 \pm 11$ seconds; $p<0.05$ ).

Platelet aggregation capacity. The aggregation capacity induced by ADP was lower before CPB in aspirin-treated platelets than in placebo-treated platelets $(p<0.05)$ but increased in aspirin-treated platelets after the onset of CPB $(p<0.05)$. The

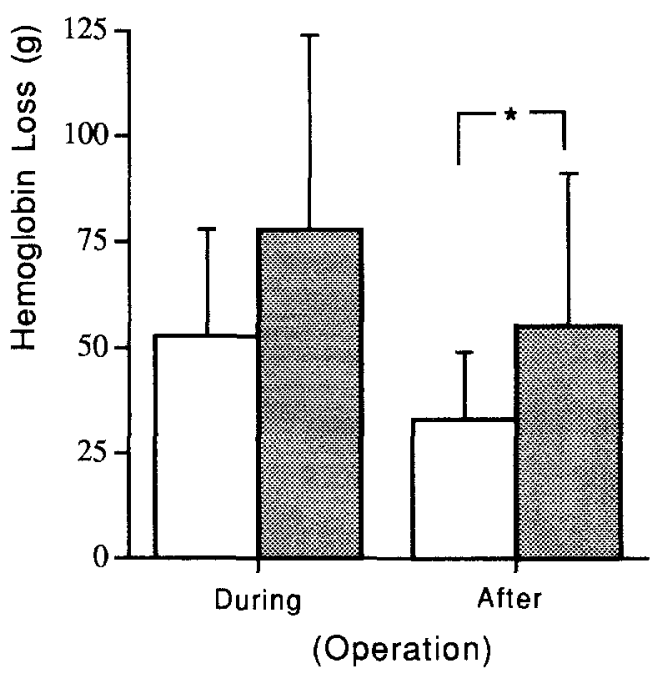

Fig. 1. Hemoglobin loss during and after operation. Hemoglobin loss was measured during and after operation in the placebo-treated group (white columns, $n=$ 18 ), and in the aspirin-treated group (dark columns, $n=$ 17). *Significant difference between groups $(p<0.05)$.

aggregation capacity induced by ADP showed no further change during CPB in either group (Fig. 3). The aggregation capacity of aspirin-treated platelets induced by collagen was consistently lower before and at the end of CPB than in the placebo-treated platelets $(p<0.05)$ (Table II).

Platelet secretory products. The plasma concentrations of thromboxane $B_{2}$ were consistently low in the aspirin-treated group, whereas they increased significantly during $\mathrm{CPB}$ in the placebo-treated group (Table III). The plasma concentrations of $\beta$-thromboglobulin increased similarly in both groups during $\mathrm{CPB}$ and reached a peak at the end of CPB (Fig. 4).

Hematologic parameters. The platelet number dropped sharply after the start of CPB, and it remained approximately $100 \times 10^{9} / \mathrm{L}$ during and after CPB in both groups, with no significant differences between the two groups at any point. No patients received transfusion of platelet concentrates during the operation. The hematocrit value decreased sharply after the start of CPB and remained constant during and after CPB. There were no significant differences in hematocrit values between the groups at any point of the study.

\section{Discussion}

According to the in vitro bleeding test, the shearinduced pathway of aspirin-treated platelets was not 


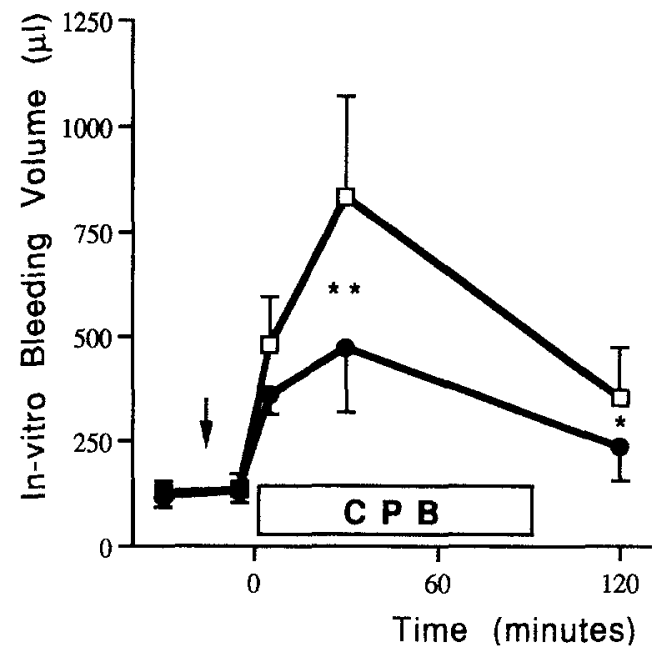

Fig. 2. The in vitro bleeding test. The in vitro bleeding volume through the capillary until the formation of a hemostatic plug is indicated against the time course of operation in the placebo-treated group (closed circles, $n$ $=8$ ) and in the aspirin-treated group (open squares, $n=$ 8). Arrow indicates injection of systemic heparin. During the first 5 minutes of $\mathrm{CPB}$, the bleeding volume increased significantly in both groups $(p<0.01)$. *Significant difference between groups $(p<0.05) .{ }^{*}$ Significant difference between groups $(p<0.01)$.

affected before CPB but became impaired after the onset of $\mathrm{CPB}$ and remained significantly worse during and after CPB compared with placebotreated platelets. The plasma $\beta$-thromboglobulin concentrations increased similarly during CPB in both groups. The aggregation capacity of aspirintreated platelets induced by ADP showed an improvement after the start of CPB and became similar to the capacity of placebo-treated platelets. This result may have been caused by some positive synergism ${ }^{14}$ between ADP and agonists such as thrombin or plasmin that are generated during CPB. ${ }^{15}$ Two contrasting phenomena of aspirintreated platelets during $\mathrm{CPB}$, the improvement of $\mathrm{ADP}$-induced aggregation and the impairment of shear-induced pathway, seem to reflect two separate pathways of platelet activation. ${ }^{8}$ Therefore, the impaired hemostasis of the aspirin-treated patients after CPB is most likely explained by the impairment of the shear-induced pathway of aspirintreated platelets during CPB.

The shear-induced pathway ${ }^{16,17}$ and the cyclooxygenase pathway ${ }^{18}$ appear to be two major pathways of platelet function contributing to hemostasis and thrombosis. ${ }^{8}$ The results of this study show that

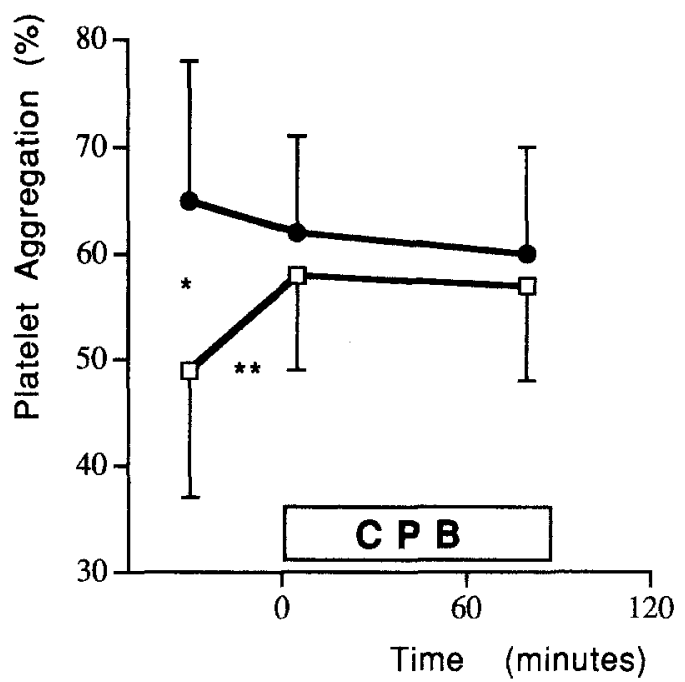

Fig. 3. Platelet aggregation induced by ADP. The maximum aggregation of aspirin-treated platelets (open squares, $n=17$ ) was lower before CPB compared with placebotreated platelets (closed circles, $n=18)(p<0.05)$ but increased after the onset of CPB $(p<0.05)$ toward the aggregation capacity of the placebo-treated platelets. *Significant difference between the groups before operation. ${ }^{*}$ Significant difference within the aspirin-treated group before operation versus after the start of CPB.

aspirin persistently inhibits thromboxane generation and collagen-induced platelet aggregation throughout the operation. Therefore, the hemostatic function of aspirin-treated patients depends mainly on the shear-induced pathway. The sequences of the shear-induced pathway of platelet function are the binding of plasma von Willebrand factor (vWF) to platelet glycoprotein $(\mathrm{Gp}) \mathrm{Ib}$, the expression of $\mathrm{GpIIb/IIIa,} \mathrm{and} \mathrm{the} \mathrm{release} \mathrm{of} \mathrm{platelet-vWF.}{ }^{16,19}$ Finally, vWF binds to GpIIb/IIIa, leading to irreversible adhesion. ${ }^{17}$ An in vitro study ${ }^{9}$ demonstrated that a high shear stress $\left(120\right.$ dyne $\left.\cdot \mathrm{cm}^{-2}\right)$ induces the immediate release of platelet-vWF multimers and the expression of GpIIb/IIIa receptors. In the presence of ADP, the released vWF multimers immediately bind to platelet receptors, ${ }^{9}$ which ensures an irreversible platelet adhesion. In a surgical wound, shear stress is estimated to be 60 dyne $\cdot \mathrm{cm}^{-2}$ in an arteriole and higher in a capillary, ${ }^{20} \mathrm{vWF}$ multimers are secreted from endothelial cells and platelets, ${ }^{21}$ and ADP is generated by cell lysis and secretion from platelets. ${ }^{22}$

The in vitro bleeding test generates a shear stress of 128 dyne $\cdot \mathrm{cm}^{-2}$, 11 which is comparable to the value estimated in a wound. It is essential to add 
Table II. Platelet aggregation capacity induced by collagen

\begin{tabular}{lccc}
\hline & $\begin{array}{c}\text { Placebo } \\
(n=18)\end{array}$ & $\begin{array}{c}\text { Aspirin } \\
(n=17)\end{array}$ & \\
\hline Before CPB & $44 \pm 24$ & $8 \pm 6$ & $p<0.05$ \\
At the end of CPB & $44 \pm 23$ & $17 \pm 16$ & $p<0.05$ \\
\hline
\end{tabular}

All values are mean \pm standard deviation.

Table III. Plasma thromboxane $B_{2}$ concentration

\begin{tabular}{lcll}
\hline & $\begin{array}{c}\text { Placebo } \\
(n=18)\end{array}$ & $\begin{array}{c}\text { Aspirin } \\
(n=17)\end{array}$ & \\
\hline Before CPB & $32.0 \pm 16.4$ & $15.4 \pm 9.6$ & $p<0.05$ \\
During CPB & & & \\
$\quad$ After 5 minutes & $96.9 \pm 54.9$ & $21.8 \pm 8.9$ & $p<0.01$ \\
$\quad$ After 30 minutes & $99.8 \pm 64.1$ & $20.8 \pm 10.0$ & $p<0.01$ \\
After CPB & $86.0 \pm 62.2$ & $12.8 \pm 5.0$ & $p<0.01$
\end{tabular}

All values are mean \pm standard deviation. Thromboxane $B_{2}$ concentrations are picograms per milliliter.

ADP on the filter, because abnormally prolonged test values have been obtained after aspirin treatment in the absence of ADP. ${ }^{13}$ The binding of released platelet-vWF induced by ADP seems to play a dominant role in platelet plug formation at this specific shear rate in the in vitro bleeding test, ${ }^{9}$ and this activation pathway is not affected by aspirin. ${ }^{8,9}$ Because alterations in the clotting system, ${ }^{23}$ in the cyclooxygenase pathway, ${ }^{24}$ and in the skin temperature $^{25}$ can affect the conventional in vivo bleeding test, the in vitro bleeding test is more specific to monitor the shear-induced pathway of platelet function.

The effects of CPB on the shear-induced pathway in normal platelets and in aspirin-treated platelets were clearly shown in this study. The abrupt increase in the in vitro bleeding volume in both groups after the start of CPB reflects mainly an altered hemostatic function of platelets and partly a hemodilution. ${ }^{10}$ The significant differences in the in vitro bleeding volume between the two groups indicate that the hemostatic function of the aspirin-treated platelets was more affected during CPB. The effect of CPB on normal platelets has been described as the loss of platelet reactivity ${ }^{26}$ and as the impairment of platelet membrane receptors $\mathrm{GpIb}^{27,28}$ or GpIIb/IIIa. ${ }^{29}$ Consequently, sensitivity to change in platelet shape is diminished during CPB, according to the morphologic study of Zilla and associates. ${ }^{30}$ Although the vulnerability of aspirin-treated platelets to CPB has not been documented previously, the typical behavior of aspirin-treated platelets dem-

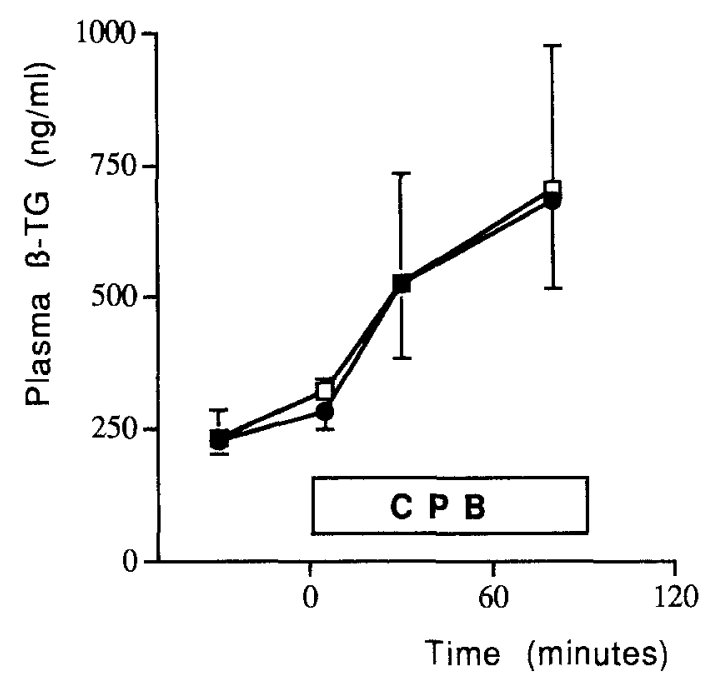

Fig. 4. Plasma $\beta$-thromboglobulin $(\beta-T G)$ concentration. The plasma concentration of $\beta$-thromboglobulin is indicated, during the operation in the placebo-treated group (closed circles, $n=18$ ) and in the aspirin-treated group (open squares, $n=17$ ).

onstrated in this study has also been shown in recent in vitro studies. ${ }^{22,31}$ Those reports described the platelet-vWF release as subtotally dependent on shape change in aspirin-treated platelets, whereas it is independent in normal platelets. Our in vitro bleeding test clearly demonstrated that the hemostatic function of aspirin-treated platelets was impaired during the initial 30 minutes of $\mathrm{CPB}$, exactly when platelets lose the sensitivity to shape change, according to the observation of Zilla's group. ${ }^{30}$ Therefore, the platelet-vWF release is a crucial step in the shear-induced platelets because of the defect in platelet shape change acquired during CPB. This could result in severe impairment of hemostasis during and after $\mathrm{CPB}$ in aspirin-treated patients.

Aspirin and placebo tablets were supplied by Bayer AG, Leverkusen, Germany. We sincerely appreciate the generous help from members of the Thorax Center of Groningen University Hospital.

\section{REFERENCES}

1. Gay WA. Aspirin, blood loss, and transfusion. Ann Thorac Surg 1990;50:345.

2. Ferraris VA, Ferraris SP, Lough FC, Berry WR. Preoperative aspirin ingestion increases operative blood loss after coronary artery bypass grafting. Ann Thorac Surg 1988;45:71-4.

3. Goldman S, Veterans Administration Group. Improvement in early saphenous vein graft patency after 
coronary artery bypass surgery with antiplatelet therapy. Circulation 1988;77:1324-32.

4. Taggart DP, Siddiqui A, Wheatly DJ. Low-dose preoperative aspirin therapy, postoperative blood loss, and transfusion requirements. Ann Thorac Surg 1990; 50:425-8.

5. Kitchen L, Erichson RB, Sideropoulos H. Effect of drug-induced prolongation of platelet dysfunction on surgical bleeding. Am J Surg 1982;143:215-7.

6. Watson CJE, Deane AE, Doyle PT, Bullock KN. Identifiable factors in post-prostatectomy haemorrhage: the role of aspirin. Br J Urol 1990;66:85-7.

7. Gavaghan TP, Gebski V, Baron DW. Immediate postoperative aspirin improves vein graft patency early and late after coronary artery bypass graft surgery. Circulation 1991;83:1526-33.

8. O'Brien JR. Shear-induced platelet aggregation. Lancet 1990;335:711-3.

9. Moake JL, Turner NA, Stathopoulos NA, Nolasco L, Hellums JD. Shear-induced platelet aggregation can be mediated by vWF released from platelets, as well as by exogenous large or unusually large vWF multimers, requires adenosine diphosphate, and is resistant to aspirin. Blood 1988;71:1366-74.

10. Tabuchi N, de Haan J, van Oeveren W. Rapid recovery of platelet function after cardiopulmonary bypass. Blood 1993;82:2930-1.

11. Kratzer MAA, Born GVR. Simulation of primary hemostasis in vitro. Haemostasis 1985;15:357-62.

12. Kratzer MAA, Bellucci S, Caen JP. Detection of abnormal platelet function with an in vitro model of primary haemostasis. Haemostasis 1985;15:363-70.

13. Kretschmer V, Schikor B, Sohngen D, Dietrich G. In vitro bleeding test: a simple method for the detection of aspirin effects on platelet function. Thromb Res 1989;56:593-602.

14. Sturk A, Asyee GM, Schaap MCL, van Maanen M, ten Cate JW. Synergistic effects of platelet-activating factor and other platelet agonists in human platelet aggregation and release. Thromb Res 1985;40:359-72.

15. Boisclair MD, Lane DA, Philippou H, et al. Mechanism of thrombin generation during surgery and cardiopulmonary bypass. Blood 1993;82:3350-7.

16. Roth GJ. Developing relationships: arterial platelet adhesion, glycoprotein $\mathrm{Ib}$, and leucine-rich glycoproteins. Blood 1991;77:5-19.

17. Ruggeri ZM. Mechanism of shear-induced platelet adhesion and aggregation. Thromb Haemost 1993;70: 119-23.
18. Rao AK, Holmsen $\mathrm{H}$. Congenital disorders of platelet function. Semin Hematol 1986;23:102-18.

19. Meyer D, Girma JP. Von Willebrand factor: structure and function. Thromb Haemost 1993;70:99-104.

20. Slack SM, Cui Y, Turitto VT. The effects of flow on blood coagulation and thrombosis. Thromb Haemost 1993;70:129-34.

21. Wanger DD. The Weibel-Palade body: the storage granule for von Willebrand factor and P-selectin. Thromb Haemost 1993;70:105-10.

22. Parker RI, Gralnick HR. Effect of aspirin on plateletvon Willebrand factor surface expression on thrombin and ADP-stimulated platelets. Blood 1989;74:201621.

23. Weiss HJ, Lages B. Studies of thromboxane $B_{2}$, platelet factor 4 , and fibrinopeptide $\mathrm{A}$ in bleedingtime blood of patients deficient in von Willebrand factor, platelet glycoprotein Ib and IIb-IIIa, and storage granules. Blood 1993;82:481-90.

24. Rodgers RPC, Levin J. A critical reappraisal of the bleeding time. Semin Thromb Hemost 1990;16:120.

25. Valeri CR, Khabbaz K, Khuri SF, et al. Effect of skin temperature on platelet function in patients undergoing extracorporeal bypass. J THORAC CARDIOvasC SuRG 1992;104:108-16.

26. Kestin AS, Valeri CR, Khuri SF, et al. The platelet function defect of cardiopulmonary bypass. Blood 1993;82:107-17.

27. van Oeveren W, Harder MP, Roozendaal KJ, Eijsman L, Wildevuur CRH. Aprotinin protects platelets against the initial effect of cardiopulmonary bypass. $J$ Thorac Cardiovasc Surg 1990;99:788-97.

28. Huang H, Ding W, Su Z, Zhang W. Mechanism of the preserving effect of aprotinin on platelet function and its use in cardiac surgery. J THORAC CARDIOVASC SURG 1993;106:11-8.

29. Wenger RK, Lukasiewicz H, Mikuta BS, Niewiarowski S, Edmunds LH. Loss of platelet fibrinogen receptors during clinical cardiopulmonary bypass. J Thorac Cardiovasc Surg 1989;97:235-9.

30. Zilla P, Fasol R, Groscurth P, Klepetko W, Reichenspurner $\mathrm{H}$, Wolner E. Blood platelets in cardiopulmonary bypass operations. J THORAC CARDIOvASC SURG 1989;97:379-88.

31. Gralnick HR, Williams SB, Mckeown LP, et al. Platelet von Willebrand Factor. Mayo Clin Proc 1991; 66:634-40. 